\title{
Medical and Dental Practitioners' Awareness about Oral-Systemic Disease Connections
}

\author{
Farrukh Imran Mian ${ }^{1}$ \\ BDS, MDS \\ Syed Ameer Hamza ${ }^{2}$ \\ BDS \\ Arsalan Wahid ${ }^{3}$ \\ BDS, MPhil \\ Syed Akhtar Hussain Bokhari ${ }^{4}$ \\ BDS, MCPS, PhD
}

OBJECTIVE: Health professionals are expected to support oral health and encourage the patients to follow appropriate dental care. Awareness and practices related to oral-systemic disease connection was assessed among medical and dental practitioners.

METHODOLOGY: A cross-sectional study on medical and dental practitioners of city Faisalabad, Pakistan was conducted. Two hundred and forty $(\mathrm{n}=240)$ medical and dental practitioners were approached for study, all practitioners rendering a consent were recruited in study and their response was collected on a close-ended questionnaire. RESULTS: Eighty three $(\mathrm{n}=83 \%)$ of respondents knew that a relationship exists between oral and systemic health, but application of this knowledge is limited. 59\% medical practitioners were in practice to look for dental conditions in medical patients in comparison to $79 \%$ dental practitioners who look into medical conditions while examining dental patients. Medical and dental professionals with post-graduate qualification had better awareness and were applying their knowledge in daily practice. Females were better in status of awareness and practice in this study sample. CONCLUSION: Level of awareness and practice about relationship of oral-systemic disease connections was moderate among the study sample, dentists showed better awareness and practice. A need is felt to improve collaboration between dental and medical profession in order to enhance patient care.

KEY WORDS: Oral-Systemic diseases, awareness, medical and dental practitioners.

HOW TO CITE: Mian FI, Hamza SA, Wahid A, Bokhari SAH. Medical and Dental Practitioners' Awareness about Oral-Systemic Disease Connections. J Pak Dent Assoc 2017;26(4):151-57.

DOI: https://doi.org/10.25301/JPDA.264.151

Received: 16 October, 2017, Accepted: 08 January, 2018

\section{INTRODUCTION}

I $\mathrm{n}$ recent years, researchers are keenly interested to understand the connection between oral and systemic diseases and its influence on patient care. World Health Organization (WHO) has reported about 200 oral manifestations of systemic diseases. ${ }^{1}$ Studies have documented relationship of oral diseases with noncommunicable diseases such as chronic respiratory diseases, diabetes, osteoporosis, cardiovascular diseases, and chronic renal failure. ${ }^{2}$ A key role in this association is played by commonality of risk factors shown by changes in systemic inflammatory mediators and body metabolism. ${ }^{3}$ However

1. Associate Professor, Department of Prosthodontics. University Medical \& Dental College, Faisalabad Pakistan.

2. Demonstrator, Department of Oral Medicine. University Medical \& Dental College, Faisalabad Pakistan.

3. Assistant Professor, Department of Oral Pathology. University Medical \& Dental College, Faisalabad Pakistan.

4. Professor, Department of Dental Public Health. University Medical \& Dental College, Faisalabad Pakistan.

Corresponding author: "Dr. Syed Akhtar Hussain Bokhari" <sahbokhari47@ hotmail.com > existing status of knowledge shows a scarcity of information and research, from developing countries, regarding the burden and association of oral and systemic diseases. ${ }^{4}$ Acute dental problems had greater impact on community in terms of work loss and restricted activity as compared to medical problems. ${ }^{5}$ Outcome of oral \& dental problems is important for both medical as well as dental professionals. Medical professionals have limited knowledge about dental aspects of general health. ${ }^{6}$ Although physicians have sufficient knowledge regarding the role of dental diseases in aggravating medical conditions but they seldom use this knowledge in their clinical practice. ${ }^{7}$

Studies have shown that most of the medical or dental problems have better prognosis if diagnosed at an early stage. ${ }^{8}$ Dental practitioners should get training to diagnose systemic problems and refer to physicians for an in time treatment. Medical professionals need to be trained to diagnose and report the dental problems so that they can resolve them at an initial stage to rule out the chances of functional restriction in individual's routine examination. 
Health professionals' knowledge and awareness about oro-dental problems and their connection with systemic conditions and some life threatening dental conditions is insufficient. ${ }^{9}$

Health professionals may play a role in promoting oral hygiene habits by spreading oral health messages, exhibiting exemplary oral health related behaviours, encouraging the patients to follow appropriate dental care. Medical professionals my participate in oral-health related activities along with their own duties. ${ }^{10}$

In social settings of developing countries, dental and medical professionals practice independently and there is very little collaboration between them regarding patient treatment except in few cases. A demand exists for additional research to appreciate status and significance of oral-systemic disease connections and prepare guidelines for their control in unindustrialized countries. ${ }^{9,11}$

Assessment of status of awareness and practice about oral-systemic disease connections among medical and dental professionals will help us to make an appropriate plan for a multi-professional approach towards an improved level of patient-care.

\section{OBJECTIVE}

Objective of this study was to assess status of awareness and practices about oral-systemic disease connections among medical and dental professionals.

\section{METHODOLOGY}

\section{Study design and Setting}

This cross-sectional study based on a standardized questionnaire was carried out among medical and dental professionals in May-June 2015. Ninety $(n=90)$ dental professionals and 150 medical professionals were randomly approached at their clinics. Two trained dental personnel explained the study objectives to potential dental / medical practitioners and who rendered their consent were enrolled in study. Institutional review board of The University of Faisalabad granted ethical approval vide letter \#TUF/BASR2014/277 dated 12.02.2014

\section{Assessment tool for evaluation of awareness and Practice}

A structured closed-ended questionnaire having 3 sections was developed. Section 1 for dental professionals that comprised of questions about their awareness with respect to systemic conditions such as skin conditions, metabolic disorders, CVD and medications; section 2 for medical professionals included questions related to their knowledge about oral conditions such as dental caries, periodontal diseases, oral trauma and tooth loss and section 3 for both dental and medical professionals regarding their awareness about oral-systemic disease connections such as periodontitis with diabetes, periodontitis with CVD and oral or systemic effect of medications. (Annex 1) Questionnaire was piloted and validated on 7 dentists and 8 physicians of Madina Teaching hospital and kappa test was noted as $87 \%$.

\section{Statistical Analysis:}

Demographic, dental and medical variables were calculated in frequencies. Systemic and oral Conditions were labeled as 'a' and ' $b$ '. Response of dental and medical practitioners was categorized into Poor (yes to $\leq 50 \%$ conditions); Fair (yes to 51-75\% conditions); and Good (yes to $>75 \%$ conditions) level of awareness and practice. Data was entered and analyzed in SPSS 20.0. Regression analysis was accomplished to see influence of gender and postgraduation. Alpha was set at $\mathrm{p} \leq 0.050$

\section{RESULTS}

\section{Demographic Parameters:}

Two hundred and forty $(n=240)$ medical and dental practitioners were approached for the study. One hundred and twenty seven practitioners who consented to be part of the study were enrolled (Response rate was 53\%). 58(46\%) medical practitioners and 69(54\%) dental practitioners participated in the study. Respondents' age ranged from 2175 years and mean age was $39.3 \pm 13.9$ year. $82(65 \%)$ were males and 45(35\%) females. 93(73\%) were graduates (BDS/MBBS) and 24(27\%) were having postgraduate qualification such as diploma / certification 14(11\%), master degree $9(7 \%)$ and $11(9 \%)$ fellowships. (Table 1)

\begin{tabular}{|c|c|c|c|}
\hline \multicolumn{4}{|c|}{$\begin{array}{l}\text { Table 1: General Characteristics of } \\
\text { Medical / Dental Practitioners }\end{array}$} \\
\hline Variables & $\begin{array}{l}\text { Medical } \\
\text { Practitioners } \\
58(46 \%)\end{array}$ & $\begin{array}{l}\text { Dental } \\
\text { Practitioners } \\
69(54 \%)\end{array}$ & $\begin{array}{l}\text { Total } \\
\text { 127(100\%) }\end{array}$ \\
\hline $\begin{array}{l}\text { Age } \\
\text { Mean } \pm \text { SD } \\
\text { Range }\end{array}$ & $\begin{array}{l}44.6 \pm 12.8 \\
21-68\end{array}$ & $\begin{array}{l}34.8 \pm 13.3 \\
21-75\end{array}$ & $\begin{array}{l}39.3 \pm 13.9 \\
21-75\end{array}$ \\
\hline $\begin{array}{l}\text { Gender } \\
\text { Males } \\
\text { Females }\end{array}$ & $\begin{array}{l}45(78 \%) \\
13(22 \%)\end{array}$ & $\begin{array}{l}37(54 \%) \\
32(46 \%)\end{array}$ & $\begin{array}{l}82(65 \%) \\
45(35 \%)\end{array}$ \\
\hline $\begin{array}{l}\text { Postgraduation } \\
\text { No } \\
\text { Certificate/Diploma } \\
\text { Masters } \\
\text { Fellowship }\end{array}$ & $\begin{array}{l}34(59 \%) \\
8(14 \%) \\
6(10 \%) \\
10(17 \%)\end{array}$ & $\begin{array}{l}59(85 \%) \\
6(9 \%) \\
3(4 \%) \\
1(1 \%)\end{array}$ & $\begin{array}{l}93(73 \%) \\
14(11 \%) \\
9(7 \%) \\
11(9 \%)\end{array}$ \\
\hline
\end{tabular}

Dental Practitioners Looking for Medical Conditions:

Seventy-nine percent $(79 \%)$ dentists (85\% graduates and $15 \%$ postgraduates) participants reported that they look 
for medical conditions while examining dental patients. Postgraduate dentists were having better level of awareness and practice about systemic diseases as compared to the graduate dentists. The highest level of awareness (98\%) was about hypertension and diabetes mellitus while the lowest level (49\%) was about Skin diseases and arthritis. Statistical significant level of difference of awareness between graduates and postgraduate was observed only for Arthritis. $(\mathrm{p} \leq 0.05)$ (Fig 1)

According to 'poor', 'fair', and 'good' categories of awareness and practice, dental practitioners were 8(11.5\%), 25(36.2\%), and $36(52 \%)$. Dental postgraduates had better awareness and practice (75\% in good category) as compared to graduates (49\% in good category, while no postgraduate was in poor category. In gender comparison, males had shown better awareness and practice in good category whereas females were better in fair category (Table 3 ).

\section{Medical Practitioners Looking for Dental Conditions:}

Fifty nine percent (59\%) were looking for dental

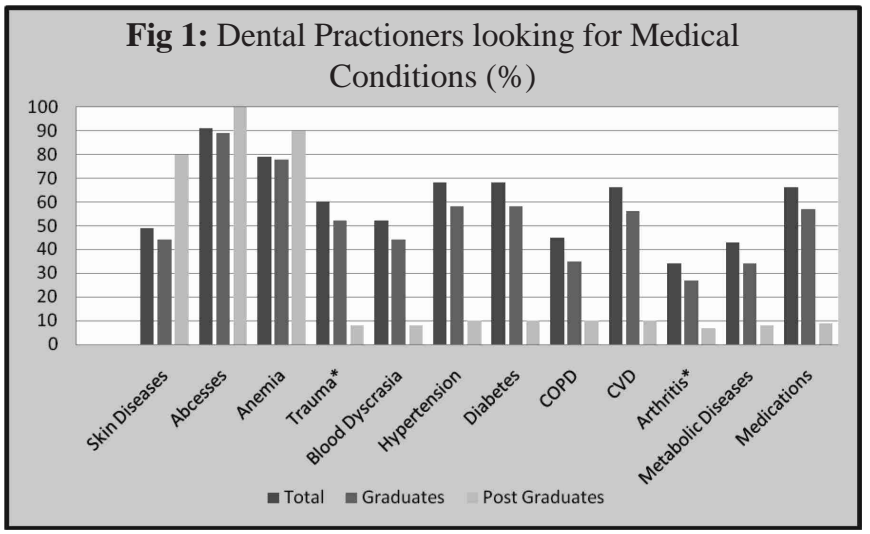

conditions. Postgraduate doctors comparatively showed a better level of awareness against graduate doctors but statistical difference was not significant regarding any disease. The highest level of awareness (86\%) was about mouth ulcers while the lowest level (38\%) was about oral sinus / fistula. (Fig 2)

According to 'poor', 'fair', and 'good' categories of

\begin{tabular}{|c|c|c|c|c|}
\hline \multicolumn{5}{|c|}{$\begin{array}{l}\text { Table 2: Medical/Dental Practitioners }(\%) \text { who understand } \\
\text { that oral and systemic conditions affect each other }\end{array}$} \\
\hline \multirow{2}{*}{$\begin{array}{l}\text { Oral/Systemic } \\
\text { Conditions and } \\
\text { Medications }\end{array}$} & \multicolumn{2}{|c|}{$\begin{array}{l}\text { Systemic conditions/Drugs } \\
\text { affect oral conditions }\end{array}$} & \multicolumn{2}{|c|}{$\begin{array}{l}\text { Oral conditions/Drugs } \\
\text { affect systemic conditions }\end{array}$} \\
\hline & $\begin{array}{l}\text { Medical } \\
\text { Practitioners } \\
\text { 58(100) }\end{array}$ & $\begin{array}{l}\text { Dental } \\
\text { Practitioners } \\
69(100)\end{array}$ & $\begin{array}{l}\text { Medical } \\
\text { Practitioners } \\
58(100)\end{array}$ & $\begin{array}{l}\text { Dental } \\
\text { Practitioners } \\
69(100)\end{array}$ \\
\hline Chronic Gingivitis & 41 & 41 & 48 & 55 \\
\hline Chronic periodontitis* & 38 & 35 & 43 & 59 \\
\hline Periapical Infections* & 43 & 36 & 38 & 56 \\
\hline Facial Space Infections* & 36 & 27 & 36 & 61 \\
\hline Diabetes & 60 & 71 & 31 & 27 \\
\hline Pregnancy & 62 & 70 & 22 & 25 \\
\hline Menstruation* & 38 & 62 & 34 & 24 \\
\hline Arthritis & 51 & 60 & 29 & 21 \\
\hline Kidney Diseases* & 46 & 68 & 38 & 20 \\
\hline Anticonvulsants & 62 & 52 & 24 & 26 \\
\hline Antibiotics & 59 & 62 & 30 & 24 \\
\hline Antihypertensives* & 36 & 68 & 41 & 22 \\
\hline Anticoagulants & 43 & 56 & 36 & 29 \\
\hline Anticholinergics & 58 & 60 & 18 & 17 \\
\hline Antidepressants & 43 & 58 & 41 & 23 \\
\hline Steroids & 51 & 68 & 37 & 24 \\
\hline Antidiabetics & 45 & 57 & 29 & 23 \\
\hline \multicolumn{5}{|c|}{$\begin{array}{l}\text { - } 36-62 \% \text { Medical practitioners whereas } 27-71 \% \text { Dental Practitioners understand that systemic } \\
\text { conditions/drugs affect oral conditions. } \\
\text { - } 18-48 \% \text { medical practitioners whereas } 17-55 \% \text { Dental Practitioners understand that oral conditions /drugs } \\
\text { affect systemic conditions. } \\
\text { - } 17 \%(8-27 \%) \text { medical practitioners and } 14 \%(4-26 \%) \text { Dental Practitioners had no idea about this oral- } \\
\text { systemic relation } \\
\text { - } \text { *Significant (p } \leq 0.048)\end{array}$} \\
\hline
\end{tabular}




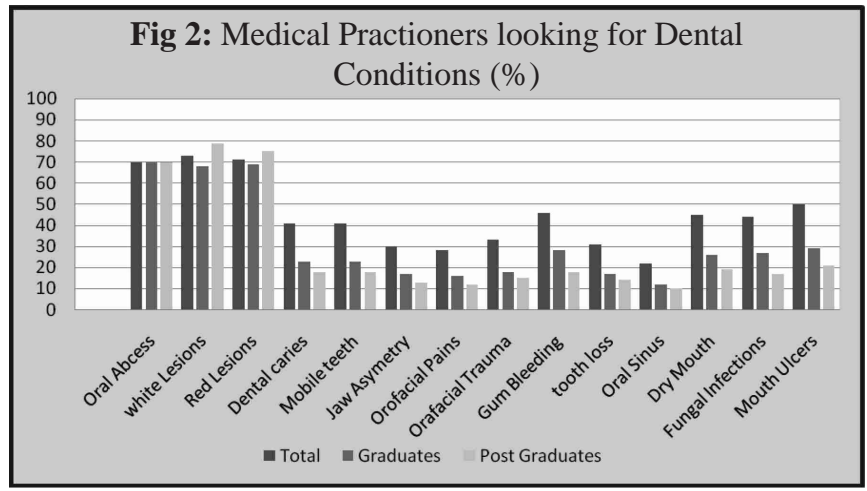

awareness and practice, distribution of medical practitioners were $20(34.4 \%), 15(25 \%)$, and 23(40\%). Medical graduates had better awareness and practice (44\% in good category) as compared to postgraduates ( $31 \%$ in good category), while less postgraduates were in poor category. In gender comparison, females had shown better awareness and practice in good category whereas males were better in fair category (Table 3).

\section{Comparison between medical and dental practitioners for having awareness related to connection of Oral and Systemic Conditions:}

Medical and dental practitioners showed a significant difference between their concepts related to chronic periodontitis, periapical infections, facial space infections, menstruation, kidney disease and anti-hypertensive medicines. $(\mathrm{p} \leq 0.048)$ 46.7\% (range 36-62\%) medical and 62\% (range $27-71 \%$ ) dental practitioners understand that systemic conditions / drugs affect oral conditions. 35\% (range $18-48 \%$ ) medical practitioners whereas $23 \%$ (range 17$55 \%$ ) dental practitioners understand that oral conditions / drugs affect systemic conditions. 17\% (8-27\%) medical practitioners and 14\% (4-26\%) dental practitioners had no idea about the oral-systemic disease relationship. (Table 2)

According to 'poor', 'fair', and 'good' categories of awareness and practice, medical practitioners were $28(22 \%)$, $40(31.4 \%)$, and $59(85 \%)$. Graduates had slightly better awareness and practice (47\% in good category) as compared to postgraduates (44\% in good category). In gender comparison, females had shown better awareness and practice in good category (49\%), fair category (33\%) and poor (18\%) as compared to males $(45 \%),(30 \%)$, and (24\%) respectively (Table 3).

Binary logistic regression analysis for having / not having knowledge of oral and systemic conditions among males and females showed a significant $(\mathrm{p} \leq 0.017)$ difference for medication, oral lesions. Tooth loss, periapical infection, kidney disease and arthritis. Binary logistic regression analysis for having / not having knowledge of oral and systemic conditions among graduates and postgraduates showed a significant $(\mathrm{p} \leq 0.017)$ difference for only systemic condition of pregnancy and oral lesions.

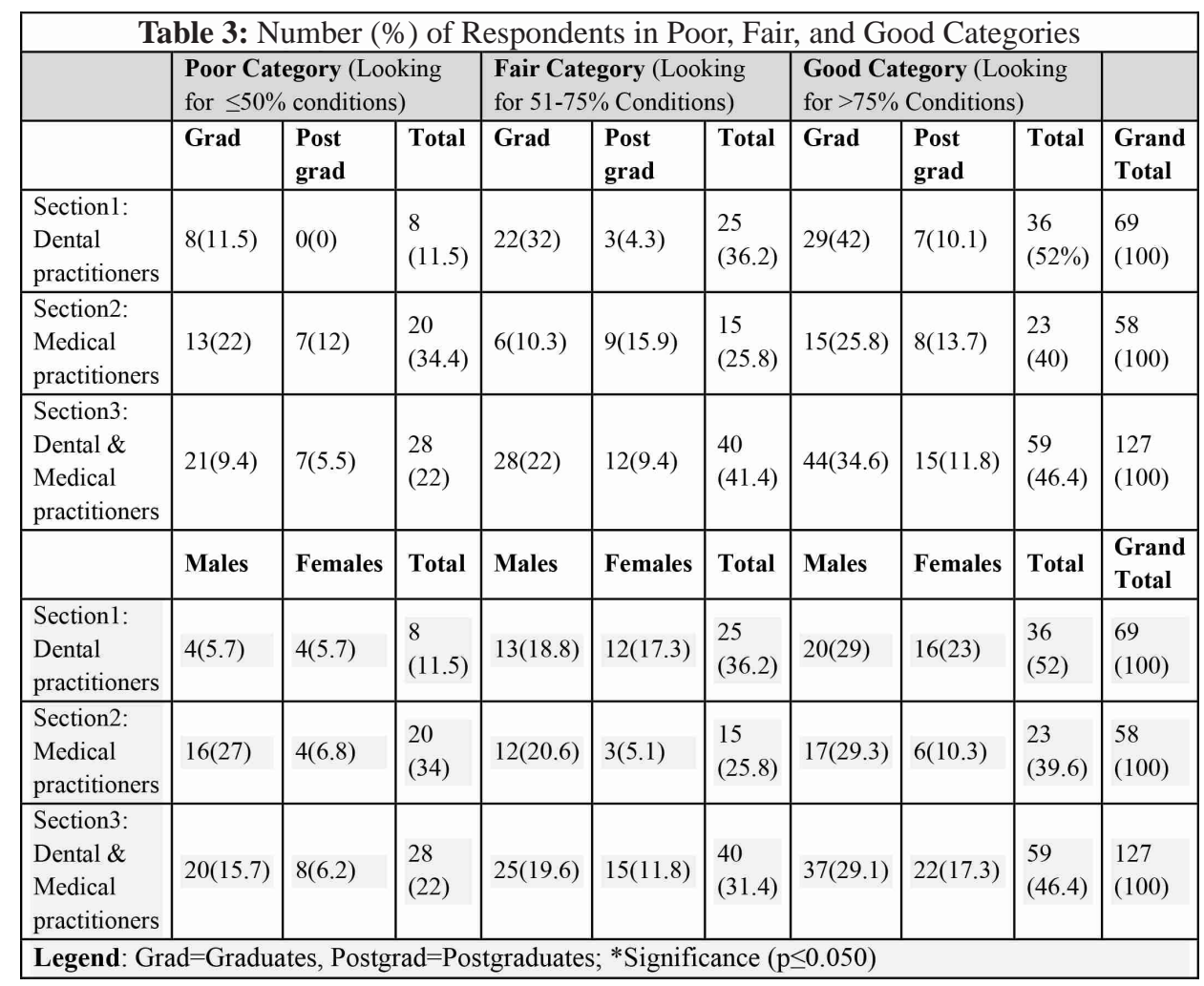




\section{DISCUSSION}

Oral health is involved in systemic conditions through the centuries, however, an understanding of the connection between oral-systemic conditions is still emerging. ${ }^{12}$ In contemporary years, the connection between oral and systemic diseases has become an important topic for research. ${ }^{13}$ Regardless of the growing information about oral-systemic connections, practicing physicians and dentists have little knowledge and poor attitude about this topic and their information needs are negligible. ${ }^{13}$ However limited studies have explored status of awareness among medical professionals regarding the relationship between oral diseases and systemic health. ${ }^{14}$ Our literature search have seen that many more studies regarding the oral health awareness of medical professionals is focused on periodontal disease.

Physicians may have a fundamental role in oral health if they are managed to have basic dental knowledge and examine oral cavity regularly for identification of many conditions at initial stages. ${ }^{15,16}$ Dentists also have some unmet medical information when they treat dental patients having systemic conditions in daily practice. Studies report that about half of the dentists observed clinical-guidelines or appropriate interventions to treat dental patient with medical co-morbidities. ${ }^{11,13}$ Oral health problems are frequently overshadowed by other health needs, which are perceived to be more obvious and urgent by the attending physician, the individual patients themselves, and their relatives. ${ }^{17}$

We have observed lack of published literature assessing the knowledge of medical and dental practitioners regarding the oral-systemic disease connections in Pakistan. This study has observed the current level of awareness about the link between oral and systemic conditions among health professionals and highlighted its importance with respect to patient care. The level of awareness shown by the respondents in this study for the yes/no knowledge questions is comparable with other studies.

Response rate (62\%) of our study well corresponds with that of a local study ${ }^{18}$ that reported a response rate of $65 \%$. A contemporary study ${ }^{19}$ also reported that most of the medical doctors had insufficient awareness regarding the association between periodontal disease and other systemic conditions and only $24 \%$ had sufficient level of awareness regarding the inter-relationship between dental and systemic diseases. In comparison to our findings, higher number of participants (90.8\%) from another study ${ }^{19}$ agreed that there was a connection between periodontal disease and systemic health.

Ninety three percent $(93 \%)$ of medical practitioners agreed that poor oral health may surge risk of cardiovascular diseases (CVD), which was however close to the percentage observed in the American study (89\%). ${ }^{3}$ These results are comparable to an Indian study conducted in Chennai where $83 \%$ of medical practitioners knew that periodontal disease is a risk factor for infective endocarditis. ${ }^{3}$ However, a study conducted in India showed only $14 \%$ of physicians who believed that periodontal disease may cause cardiac heart diseases. ${ }^{20}$ In concordance with our study, most physicians had general knowledge about periodontal disease. ${ }^{21}$

In a study ${ }^{22}$ from India, stated that general practitioners \& Gynecologists had good level of awareness regarding relationship between periodontal disease and preterm low birth weight babies. A Nigerian study revealed that it was only in the cases of DM, rheumatic heart disease, valvular heart disease, and HIV/AIDS that more than $50 \%$ of the doctors strongly agreed that there is a possible causal link between oral diseases and systemic condition of individual patient. ${ }^{23}$ This is against the widely reported possible links between many of these conditions and the oral health. In this study, majority of the female respondents claimed ignorance of any possible relationship between oral disease and myocardial infarction.

The Nigerian study ${ }^{23}$ has concluded that doctors' perception of the influence of dental disease/condition on the general state of patients' health was deficient and, therefore, requires improvement through health education and awareness. Patel and Driscoll ${ }^{24}$ has shown limited dental knowledge by the physicians. In another study from India, ${ }^{25}$ dental knowledge of physicians was however considered to be good and the authors concluded that this could have been due to the inclusion of dental posting in the curriculum of medical students, moreover postgraduates have shown better knowledge. Therefore, it is quite reasonable that health professionals such as physicians, family doctors should participate in oral health promotion programs. Medical professionals evidently need practical and theoretical training in oral health, predominantly targeting the prevention and identification of periodontal disease being chronic, infectious and inflammatory in nature. MBBS curriculum in India contains a dental component, which gives an introduction to oral health aspects that increases the knowledge and awareness about dentistry; therefore Indian medical practitioners show a good attitude about dentistry. ${ }^{25}$ Training programs should ideally be offered during graduation and post-graduation programs, particularly in multi-professional internship programs. Another factor that has been put forward as being helpful in creating dental awareness among the physicians is the continuing medical education programs jointly organized for both the medical and dental practitioners in order to update their knowledge. ${ }^{25,26}$

General medical practitioner is the first contact for most of the patients. ${ }^{15}$ Examination of oral cavity by a doctor is 
an accepted part of physical examination for a long time, and if it is carried out in routine it can substantially reduce the morbidity and mortality resulting from oral conditions. ${ }^{26}$ Morgan et al. ${ }^{15}$ observed that majority of doctors of their study considered it important to examine the patients' mouths. But in our study, only $19 \%$ of the doctors $(\mathrm{p}=0.0001)$ routinely did so. A moderate level of oral health awareness among the medical practitioners has been reported, ${ }^{27}$ however an insignificant difference was noted between the practitioners with different qualifications and extents of experience. Potential effects of many systemic ailments on periodontal tissues are well recognized, through current evidence suggests that periodontal infections can significantly raise risk for many systemic disorders and/or modify the natural way of systemic illnesses. $^{28,29}$

In our study, $83 \%$ of respondents knew that a relationship exists between oral and general health, but application of this knowledge is limited. Therefore, need for a multiprofessional approach and integration of health promoting strategies have been emphasized ${ }^{30}$ and oral health promotion has been desired within health care practices of physicians. ${ }^{20}$ A study has reported that $78 \%$ physicians admitted that their general knowledge about oral health is insufficient and neither gender nor age difference was noted in that study. ${ }^{31}$ Age difference was not observed in this study, females have shown better level of awareness and practice in this study sample. A statistical difference of $\mathrm{p}=0.032$ was noted among medical and dental practitioners for having awareness and practicing oral-systemic disease connection, however there was no difference with respect to graduates and postgraduates.

\section{CONCLUSION}

Level of awareness and practice about relationship of oral-systemic disease connections was moderate among the study sample, dentists showed better awareness and practice. This indicates that there is need to improve collaboration between dental and medical profession in order to enhance patient care and recommend inclusion of dental health related items in MBBS curriculum.

\section{CONFLICT OF INTEREST}

None declared

\section{REFERENCES}

1. Wahid A, Chaudhry S, Ehsan A, Butt S, Khan AA. Bidirectional Relationship between Chronic Kidney Disease \& Periodontal Disease. Pak J Med Sci 2013;29:211-5 2. Bokhari SA, Khan AA. Growing burden of noncommunicable diseases: the contributory role of oral diseases, Eastern Mediterranean Region perspective. East Mediterr Health J 2009; 15:1011-20.

3. Asaad Farah A-MN, Alelyan Bushra, Asaad Lama, Alrumaih Walaa, Alassad Fatimah, Alshakhs Sara, et al. Knowledge and orientations of medical interns toward periodontal disease in Saudi Arabia. Saudi J Oral Sci 2014;1:98-104.

4. Boutayeb A, Boutayeb S. The burden of non communicable diseases in developing countries. Int J Equity Health 2005: 14:2-5

5. Hayes A, Azarpazhooh A, Dempster L, Ravaghi V, Quinonez C. Time loss due to dental problems and treatment in the Canadian population: analysis of a nationwide crosssectional survey. BMC Oral Health 2013.13:17. 6. Nagarakanti S, Epari V, Athuluru D. Knowledge, attitude, and practice of medical doctors towards periodontal disease. J Indian Soc Periodontol. 2013;17(1):137-9. 7. Reid G, Jass J, Sebulsky MT, McCormick JK. Potential uses of probiotics in clinical practice. Clin Microbiol Rev. 2003;16:658-72.

8. Chandna S, Bathla M. Oral manifestations of thyroid disorders and its management. Indian J Endocrinol Metab 2011;15:S113-6.

9. Zhang S, Lo EC, Chu CH. Attitude and Awareness of Medical and Dental students towards collaboration between medical and dental practice in Hong Kong. BMC oral Health 2015;15:53

10. Ingledew DK, Brunning S. Personality, Preventive Health Behaviour and Comparative Optimism about Health Problems. J Health Psychol 1999;4:193-208. 11. Mathers CD, Bernerd C, Iburg KM, Inoue M, Fat DM, Shibuya K, et al. Global Burden of Disease in 2002 data sources, methods and results. 2002 Paper 54 WHO. 12. Ford PJ, Raphael SL, Cullinan MP, Jenkins AJ, West MJ, Seymour GJ. Why should a doctor be interested in oral disease? Expert Rev Cardiovasc Ther 2010;8:1483-93. 13. Song M, O'Donnell JA, Bekhuis T, Spallek H. Are dentists interested in the oral-systemic disease connection? A qualitative study of an online community of 450 practitioners. BMC Oral Health 2013;13:65. 14. Al-Khabbaz AK, Al-Shammari KF, Al-Saleh NA. Knowledge about the association between periodontal diseases and diabetes mellitus: contrasting dentists and physicians. J Periodontol 2011;82:360-6.

15. Morgan R, Tsang J, Harrington N, Fook L. Survey of hospital doctors' attitudes and knowledge of oral conditions in older patients. Postgrad Med J 2001;77:392-4. 16. Patel MC, Sujan SG. The prevalence of traumatic dental injuries to permanent anterior teeth and its relation with predisposing risk factors among 8-13 years school children 
of Vadodara city: an epidemiological study. J Indian Soc Pedod Prev Dent 2012;30:151-7.

17. Niesten D, van Mourik K, van der Sanden W. The impact of frailty on oral care behavior of older people: a qualitative study. BMC Oral Health 2013;13:61.

18. Shah MN, Khan MA, Shah F. Tooth Brushing Habits And Knowledge Among Patients Visiting Khyber College Of Dentistry. J Khyber Coll Dent 2015;5:12-15 19. Tasdemir Z, Alkan BA. Knowledge of medical doctors in Turkey about the relationship between periodontal disease and systemic health. Braz Oral Res 2015;29:55. 20. Garcia RI, Cadoret CA, Henshaw M. Multicultural issues in oral health. Dent Clin North Am 2008;52:319-32 21. Bastos Jdo A, Vilela EM, Henrique MN, Daibert Pde C, Fernandes LF, Paula DA. Assessment of knowledge toward periodontal disease among a sample of nephrologists and nurses who work with chronic kidney disease not yet on dialysis. J Bras Nefrol 2011;33:431-5.

22. Tarannum F, Prasad S, Vivekananda L, Jayanthi D, Faizuddin M. Awareness of the association between periodontal disease and pre-term births among general dentists, general medical practitioners and gynecologists. Ind J Pub Health 2013;57:92-5.

23. Opeodu OI, Dosumu EB, Arowojolu MO. Periodontal
Condition and Treatment Needs of Some Pregnant Women in Ibadan, Nigeria. Ann Med Health Sci Res 2015;5:213-7. 24. Patel KK, Driscoll P. Dental knowledge of accident and emergency senior house officers. Emerg Med J. 2002;19:53941.

25. Srinidhi S, Chaly PE, Reddy C. Dental awareness and attitudes among medical practitioners in Chennai. . J Oral Health Comm Dent. 2011;5:73-8.

26. Jovanovic A SE, van der Waal I. Referral pattern of patients with oral mucosal lesions in The Netherlands. Community Dent Oral Epidemiol 1992;20:94-6. 27. Sarumathi T, Saravanakumar B, Datta M, Nagarathnam T. Awareness and knowledge of common oral diseases among primary care physicians. J Clin Diagn Res 2013;7:768-71. 28. Mealey BL. Influence of periodontal infections on systemic health. Periodontol 2000 2000;21:197-209. 29. Page RC, Beck JD. Risk assessment for periodontal diseases. Int Dent J 1997;47:61-87.

30. Ramirez JH, Arce R, Contreras A. Why must physicians know about oral diseases? Teach Learn Med. 2010;22:14855.

31. Rabiei S, Mohebbi SZ, Patja K, Virtanen JI. Physicians' knowledge of and adherence to improving oral health. BMC Public Health 2012.12:855. 